\title{
Seasonal trends of indoor particulate matter concentrations in a naturally ventilated school building
}

\author{
V. S. Chithra \& S. M. Shiva Nagendra \\ Department of Civil Engineering, \\ Environmental and Water Resources Engineering Division, \\ Indian Institute of Technology Madras, India
}

\begin{abstract}
This paper presents the seasonal trends in indoor particulate matter $\left(\mathrm{PM}_{10}, \mathrm{PM}_{2.5}\right.$ and $\mathrm{PM}_{1}$ ) concentrations measured at a naturally ventilated school building located close to an urban roadway in Chennai city. The indoor $\mathrm{PM}_{10}, \mathrm{PM}_{2.5}$ and $\mathrm{PM}_{1}$ concentrations were monitored over a period of 106 days during winter, summer and monsoon seasons. Daily average $\mathrm{PM}_{10}, \mathrm{PM}_{2.5}$ and $\mathrm{PM}_{1}$ concentrations inside the building were found to be $171,53,33 ; 128,42,20$ and $142,51,32 \mu \mathrm{g} / \mathrm{m}^{3}$, respectively during winter, summer and monsoon seasons. The indoor PM concentrations were varied with outdoor meteorological conditions, traffic emissions and indoor activities. Correlation between indoor and outdoor $\mathrm{PM}_{10}$ showed poor $\left(\mathrm{R}^{2}=0.36\right)$ and moderate $\left(\mathrm{R}^{2}=0.6\right)$ during working (8.00-16.00) and non working hours (16.00-8.00), respectively. Whereas, the indoor and outdoor fine $\mathrm{PM}\left(\mathrm{PM}_{2.5}\right.$ and $\left.\mathrm{PM}_{1}\right)$ levels showed good correlation irrespective of time period $\left(\mathrm{R}^{2}=0.7-0.83\right)$, indicating that infiltration of vehicular emitted fine particles into indoors. The PM data analysis showed a strong seasonal influence with maximum values during winter and monsoon seasons coinciding with stagnant atmospheric conditions (low wind speed and temperature) and minimum during summer.

Keywords: indoor air quality, particulate matter, school, meteorology, resuspension.
\end{abstract}




\section{Introduction}

In the recent past, many epidemiological studies have reported that exposure to particulate matter (PM) have adverse health effects and will cause a number of respiratory and cardiovascular diseases. [1-4]. Coarser particles (aerodynamic diameter greater than $10 \mu \mathrm{m}$ ) are primarily irritants and may not have much relevance to direct health consequences. Whereas, respirable particles (aerodynamic diameter less than $10 \mu \mathrm{m}$ ) can penetrate deep into the human respiratory system and are removed more slowly from the body [5]. Particulate matter is one of the major air pollutants in most of the cities in India and it is often exceeding the permissible limits in many locations [6]. It is also well documented in various investigations that PM has substantial impacts on human health in India [7, 8]. Recently, Central Pollution Control Board (CPCB) revised the National Ambient Air Quality Standards (NAAQS) of India and introduced $\mathrm{PM}_{2.5}$ regulations. Although numerous measurements of ambient particulate matter have been conducted in Indian cities, only limited data was available about its concentration in the indoor environment, where people spend most of their time.

Most of the schools in the developing countries like India are naturally ventilated, allowing particles from outdoors to readily penetrate the classroom through given spaces and cracks in the structure. Meteorology affects particle size distributions and concentration in different ways. A number of studies have been devoted to characterize the relationship between indoor and outdoor air quality. Most of the studies reported have focused on chemical composition, indoor outdoor ratios, spatial variation and source apportionment studies, but studies on seasonal variation which are long term studies are less $[9,10]$. It is felt that the problem of indoor air quality with respect to meteorology is an area which is not properly addressed. In this study, we attempt to understand the relationships between meteorological parameters and the size-dependent effects on indoor PM levels.

\section{Methodology}

Chennai $\left(13.04^{\circ} \mathrm{N} 80.17^{\circ} \mathrm{E}\right)$, the capital City of Tamil Nadu is the fourth largest Metropolitan City in India. The city lies on the thermal equatorand is also on the coast, which prevents extreme variation in seasonal temperature. Chennai has tropical climate and the weather is hot and humid for most of the year. According Indian meteorological department, the hottest part of the year is late May to early June with daily maximum temperature of $36.6^{\circ} \mathrm{C}$. The coolest month of the year is January, with a daily minimum temperature of $20.6^{\circ} \mathrm{C}$. Chennai gets most of the rain during the northeast monsoons, in October and November. Less rainfall occurs during the southwest monsoon since Chennai is in a rain shadow region caused by mountains along the west coast of India. 


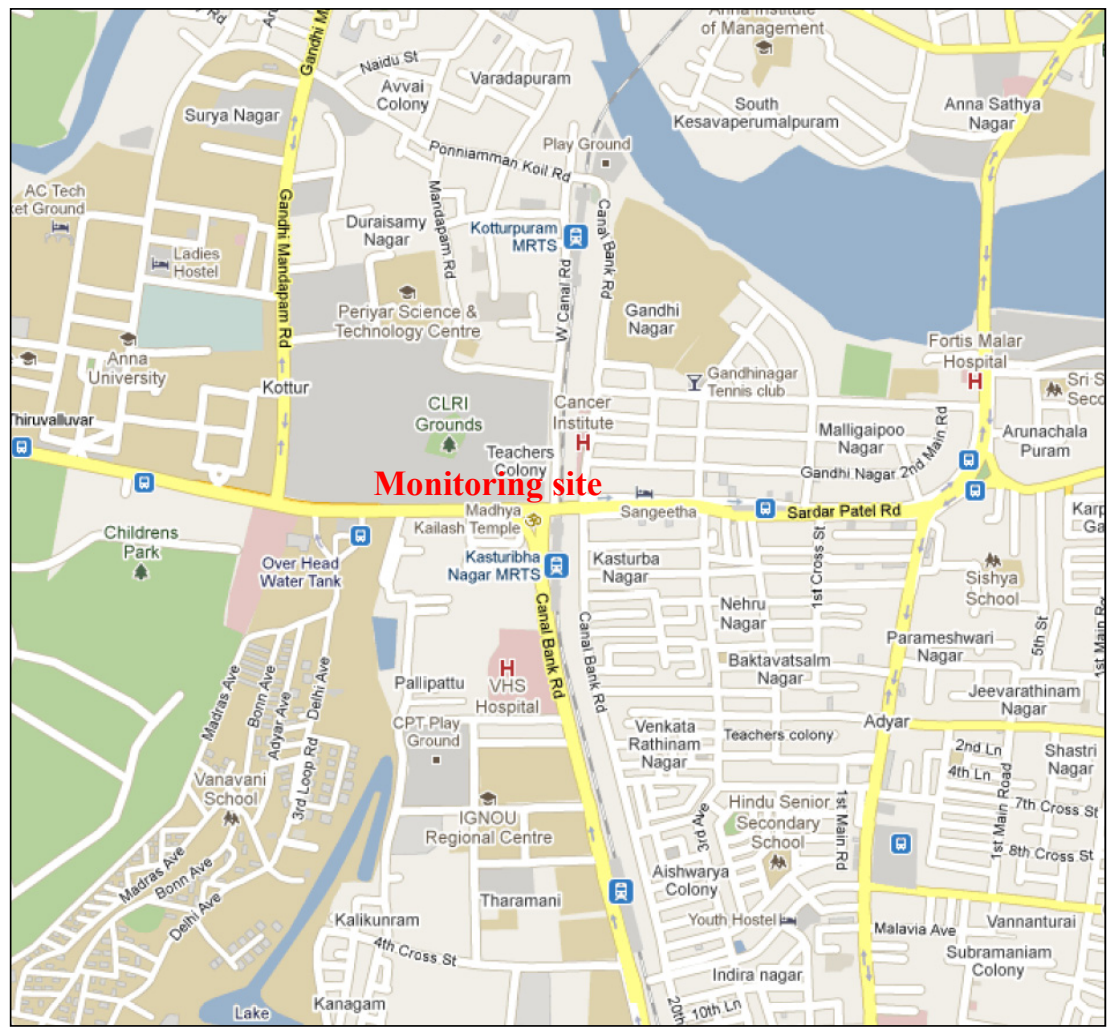

Figure 1: Monitoring site.

The school building selected for the present study was located near a busy road with an average traffic flow of about 173,000 vehicles/day during weekdays and 141,000 vehicles/day during weekends. (The monitoring site is presented in Figure 1.) The classroom selected was on a top floor of two-storey building with dimensions of $7.3 \times 5.6 \times 3 \mathrm{~m}$. It was naturally ventilated through four windows and one door, in which windows were permanently left open. Classrooms were occupied by 43 pupils (age group of $8-9$ years) on weekdays, usually from 8.00 to 16.00 hours. The sampling was done for 106 days during winter (JanuaryFebruary), summers (April-May) of 2012 and monsoon (October-December) seasons of 2011. For measuring the airborne particulate matter, portable optical Grimm dust monitor (Grimm Labortechnik Ltd., Ainring, Germany, Model 1.107 and 1.108,) was used. The ambient air drawn into the unit via an internal volume controlled pump at a rate of $1.2 \mathrm{~L} / \mathrm{min}$. Gravimetric calibration is accomplished by measuring the actual mass of dust collected on a back-up $47 \mathrm{~mm}$ PTFE, $0.2 \mu \mathrm{m}$ pore size filter. During the monitoring campaigns $1-\mathrm{min}$ average concentrations of $\mathrm{PM}_{10}, \mathrm{PM}_{2.5}$ and $\mathrm{PM}_{1}$ have been recorded on a data storage card: $1-\mathrm{h}$ and daily average concentrations have been subsequently calculated based on the recorded data. The samplers were placed $1 \mathrm{~m}$ above the 
floor level. Outdoor samplers were located near the kerbside. Meteorological parameters (wind speed, wind direction and temperature) were collected from the meteorological station (WM251, Envirotech), which was installed at the rooftop of school building. Relative humidity data for the monitoring period was obtained from nearby CPCB monitoring station. Daily average rainfall data of Chennai was downloaded from Indian Meteorological department website [12].

\section{Results and discussion}

\subsection{Hourly average indoor and outdoor PM concentrations}

The relationships between indoor and outdoor PM concentrations were investigated using linear regression analysis. Fig. 2 represents the correlation between indoor and outdoor PM concentrations during working hours (8.00 to $16.00)$ and nonworking hours (16.00 to 8.00). The $\mathrm{PM}_{10}$ concentrations were found to be significantly higher when class room was occupied when it was compared to unoccupied. It was found that indoor verses outdoor $\mathrm{PM}_{10}$ showed moderate correlation $\left(\mathrm{R}^{2}=0.6\right)$ and poor correlation $\left(\mathrm{R}^{2}=0.36\right)$ during working and non working hours, respectively. On the other hand indoor $\mathrm{PM}_{2.5}$ and $\mathrm{PM}_{1}$ showed good correlation with its outdoor concentrations, irrespective of time period. This indicates that coarse and fine particles are contributed from different sources at the study site. The coarse particle may be linked to re-suspension of particles due to class room activities such as movement of students and teacher inside the classroom, sweeping etc and fine particle can be linked to outdoor traffic. Many authors were also reported that human activities have significant effect on indoor coarser particles concentrations [13-18].

The diurnal pattern of indoor $\mathrm{PM}_{10}$ varied depending on classroom activities. On the other hand, the indoor and outdoor $\mathrm{PM}_{2.5}$ and $\mathrm{PM}_{1}$ concentration were strongly influenced by the traffic density. Indoor and outdoor PM concentration exhibited two peaks during morning and evening hours. The morning peak occurred between 09:00 $\mathrm{h}$ and 11:00 $\mathrm{h}$ with an average vehicle count of 11,779 for weekdays and 7402 for Sunday. In weekdays, during morning peak hours, the average indoor and outdoor $\mathrm{PM}_{10}, \mathrm{PM}_{2.5}$ and $\mathrm{PM}_{1}$ concentrations were 337; 59; $23 \mu \mathrm{g} / \mathrm{m}^{3}$ and $109 ; 41 ; 25 \mu \mathrm{g} / \mathrm{m}^{3}$, respectively. It was observed that the indoor $\mathrm{PM}_{10}$ concentrations were significantly higher than outdoor. It is not only due to traffic emissions but also contributed from the re-suspension of particles due to the movement of students and teachers. The peak of indoor $\mathrm{PM}_{10}$ concentrations occurring at 12:00-13:00h was also not reflected in the outdoor profile, i.e. the elevated concentration of indoor particles observed during noon-early afternoon was more likely due to the indoor particle activities rather than the transport from outdoors. The evening peak occurred around 18:00-20.00h with an average vehicle count of 10,671 for weekdays and 8,476 for Sunday. During Sundays the evening peak traffic flow was slightly higher than that of morning peak hour traffic. Whereas, on other days morning peak traffic was higher than that of evening peak traffic flow, which was reflected in the indoor and outdoor PM concentrations. During morning peak hours on Sundays, the average indoor and 
(a)
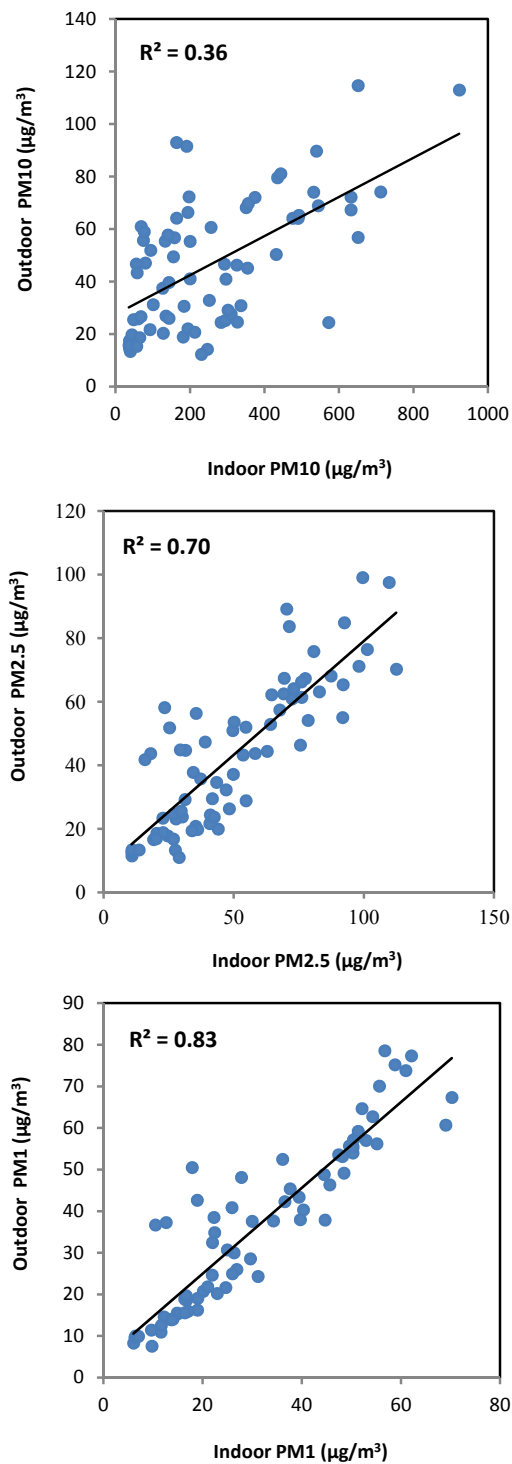

(b)
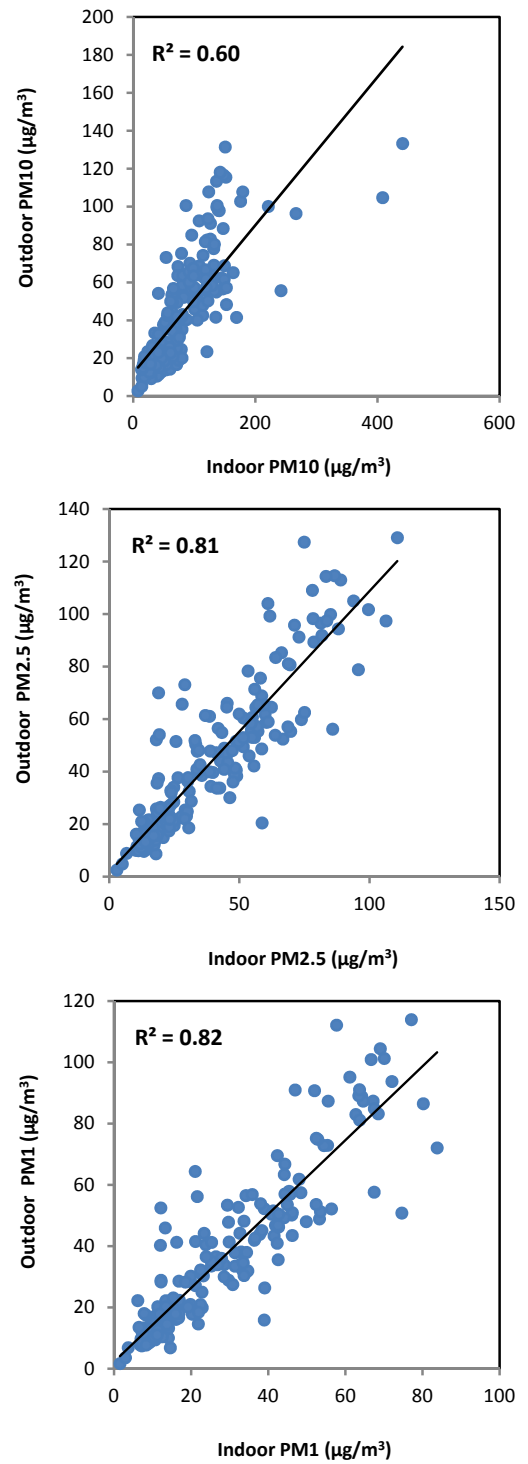

Figure 2: Correlation between indoor and outdoor PM concentrations (a) non working hours (b) working hours.

outdoor $\mathrm{PM}_{10}, \mathrm{PM}_{2.5}$ and $\mathrm{PM}_{1}$ concentrations were $82 ; 25 ; 12 \mu \mathrm{g} / \mathrm{m}^{3}$ and $52 ; 19$; $11 \mu \mathrm{g} / \mathrm{m}^{3}$, respectively. Weekly behaviours observed for PM concentration shows a progressive increase of the daily concentration, reaching a maximum on weekdays, followed by a downward trend towards the minimum observed on 
Sundays. Sundays' indoor $\mathrm{PM}_{2.5}, \mathrm{PM}_{1}$ concentration levels are on average about 26 and $29 \%$ lower than that of weekdays, respectively.

\subsection{Daily average indoor PM concentrations}

Daily average indoor PM concentrations and meteorological parameters during different seasons were summarized in table 1. The $\mathrm{PM}_{10}, \mathrm{PM}_{2.5}$ and $\mathrm{PM}_{1}$ concentration inside the building were found to be 171, 53, 33; 128, 42, 20 and $142,51,32 \mu \mathrm{g} / \mathrm{m}^{3}$, respectively during winter, summer and monsoon seasons. Average indoor and outdoor $\mathrm{PM}_{10}$ and $\mathrm{PM}_{2.5}$ concentrations were found to be exceeding the WHO air quality guidelines $\left(50 \mu \mathrm{g} / \mathrm{m}^{3}\right.$ for $\mathrm{PM}_{10}$ and $25 \mu \mathrm{g} / \mathrm{m}^{3}$ for $\mathrm{PM}_{2.5}$ ) for all the seasons. Indoor $\mathrm{PM}_{10}$ concentrations were also exceeded CPCB standard $\left(100 \mu \mathrm{g} / \mathrm{m}^{3}\right)$. While its outdoor concentrations were within the limits expect for winter season.

Table 1: Descriptive statistics of particulate matter concentrations and meteorological parameters during different seasons $(I=$ No. of indoor monitoring days; $\mathrm{O}=$ No. of outdoor monitoring days).

\begin{tabular}{|c|c|c|c|c|c|c|c|c|c|c|}
\hline \multirow[t]{2}{*}{ Season } & \multirow{2}{*}{$\begin{array}{l}\text { Statis- } \\
\text { tics }\end{array}$} & \multicolumn{3}{|c|}{ Indoor } & \multicolumn{6}{|c|}{ Outdoor } \\
\hline & & $\begin{array}{l}P_{10} \\
\left(\mu \mathrm{g} / \mathrm{m}^{3}\right)\end{array}$ & $\begin{array}{l}P_{2.5} \\
\left(\mu \mathrm{g} / \mathrm{m}^{3}\right)\end{array}$ & $\begin{array}{l}\mathbf{P M} \mathbf{M}_{1} \\
\left(\mu \mathrm{g} / \mathbf{m}^{3}\right)\end{array}$ & $\begin{array}{l}P_{10} \\
\left(\mu \mathrm{g} / \mathbf{m}^{3}\right)\end{array}$ & $\begin{array}{l}P_{2.5} \\
\left(\mu \mathrm{g} / \mathrm{m}^{3}\right)\end{array}$ & $\begin{array}{l}P M_{1} \\
\left(\mu \mathrm{g} / \mathrm{m}^{3}\right)\end{array}$ & $\begin{array}{l}\text { Tempe } \\
\text { rature } \\
\left({ }^{\circ} \mathbf{C}\right) \\
\end{array}$ & \begin{tabular}{|l} 
Relative \\
humidity \\
(\%)
\end{tabular} & $\begin{array}{l}\text { Wind } \\
\text { speed* } \\
\text { (m/s) }\end{array}$ \\
\hline \multirow{6}{*}{\begin{tabular}{|l|} 
Monsoon \\
(Oct- \\
Dec) \\
$\mathrm{I}=48$ \\
$\mathrm{O}=28$ \\
\end{tabular}} & Max & 303.13 & 114.72 & 84.35 & 196.30 & 75.91 & 66.43 & 29.4 & 87.34 & 1.44 \\
\hline & Min & 24.59 & 13.33 & 7.52 & 19.16 & 17.83 & 14.20 & 23.75 & 76.26 & 0 \\
\hline & Mean & 142.23 & 51.24 & 35.13 & 72.19 & 40.85 & 32.56 & 26.70 & 80.57 & 0.23 \\
\hline & Median & 126.89 & 41.00 & 31.73 & 45.26 & 33.12 & 26.26 & & & \\
\hline & & & & & & & & 27.01 & 81.23 & 0.11 \\
\hline & SD & 82.13 & 28.69 & 20.99 & 60.43 & 19.48 & 16.85 & 2.06 & 3.44 & 0.29 \\
\hline \multirow{5}{*}{$\begin{array}{l}\text { Winter } \\
\text { (Jan- } \\
\text { Feb) } \\
\mathrm{I}=25 \\
\mathrm{O}=3\end{array}$} & Max & 402.85 & 103.65 & 53.85 & 160.54 & 54.81 & 39.34 & 27.60 & 79.40 & 0.65 \\
\hline & Min & 70.17 & 24.45 & 11.81 & 153.93 & 51.74 & 35.99 & 21.60 & 50.97 & 0.00 \\
\hline & Mean & 170.60 & 52.62 & 32.57 & 157.24 & 53.27 & 37.66 & 24.98 & 73.73 & 0.36 \\
\hline & Median & 134.34 & 44.06 & 33.55 & 157.24 & 53.27 & 37.66 & 24.93 & 77.48 & 0.28 \\
\hline & SD & 91.60 & 20.81 & 10.39 & 4.67 & 2.17 & 2.36 & 1.53 & 8.61 & 0.19 \\
\hline \multirow{5}{*}{$\begin{array}{l}\text { Summer } \\
\text { (April- } \\
\text { May) } \\
\mathrm{I}=33 \\
\mathrm{O}=21\end{array}$} & Max & 221.43 & 66.74 & 38.20 & 167.94 & 64.85 & 43.14 & 31.10 & 77.68 & 1.19 \\
\hline & Min & 49.80 & 15.90 & 7.43 & 25.96 & 15.66 & 10.89 & 28.37 & 64.94 & 0.00 \\
\hline & Mean & 128.35 & 41.65 & 19.87 & 86.51 & 34.83 & 21.22 & 29.81 & 72.31 & 0.82 \\
\hline & Median & 124.93 & 44.79 & 20.23 & 75.02 & 30.45 & 20.82 & 29.61 & 72.41 & 0.81 \\
\hline & SD & 41.91 & 15.75 & 7.81 & 38.68 & 12.91 & 7.73 & 0.65 & 3.07 & 0.21 \\
\hline
\end{tabular}

*hourly average. 


\subsection{Seasonal trends of indoor PM}

A significant difference in PM was noticed between the winter, summer and monsoon period, with maximum values during winter and monsoon coinciding with stagnant atmospheric conditions (low wind speed and temperature) and minimum during summer. Detailed discussion on the relationship between indoor particulate matter $\left(\mathrm{PM}_{10}, \mathrm{PM}_{2.5}\right.$ and $\left.\mathrm{PM}_{1}\right)$ and outdoor meteorological parameters like wind speed, temperature, relative humidity and precipitation are presented in the following section.

\subsubsection{Effects of wind speed}

Wind speed plays a major role on the seasonal variation of particulate matter concentrations. The lowest wind speeds are observed during the monsoon $(0.23 \mathrm{~m} / \mathrm{s})$ and winter $(0.36 \mathrm{~m} / \mathrm{s})$. Wind speed frequency distribution at monitoring station shows that, the major prevailing wind directions are frequent from the northwest and southeast. During winter predominant wind direction was northwest. Southeast wind was found maximum frequency during summer.

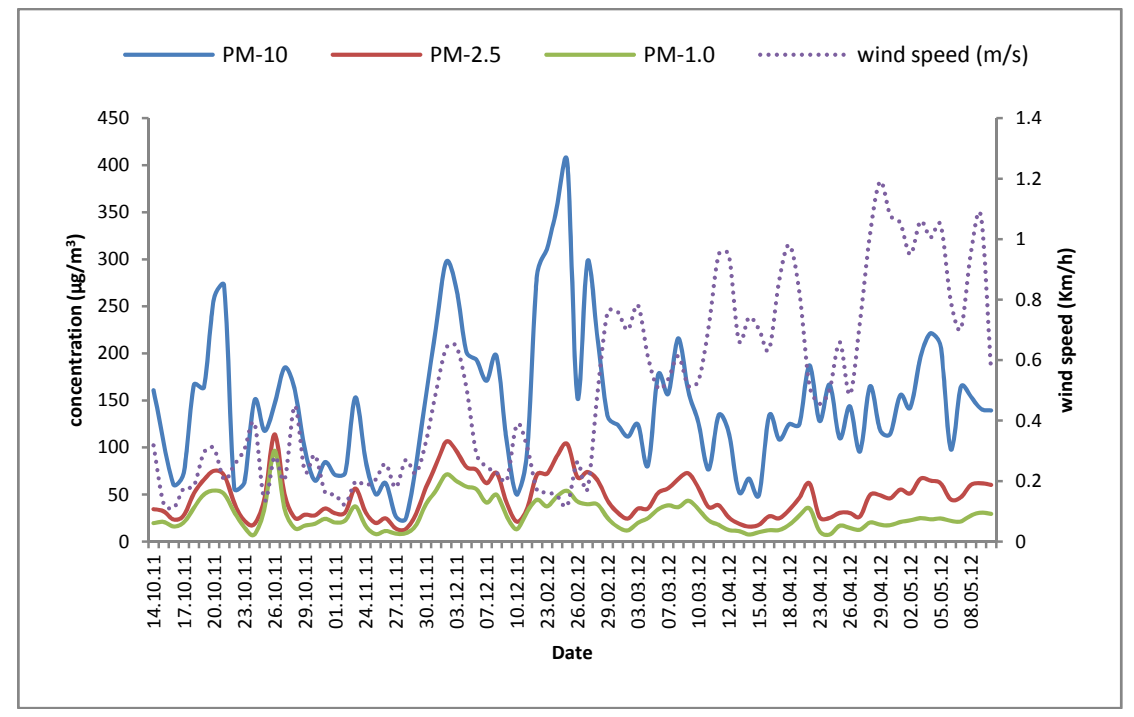

Figure 3: Time series of PM concentrations and wind speed.

During monsoon the wind direction fluctuates between northwest and southeast directions. The calm condition was the highest in monsoon and the lowest in summer. Time series of $\mathrm{PM}_{10}, \mathrm{PM}_{2.5}, \mathrm{PM}_{1}$ and wind speed is shown in figure 3. It can be seen from the figure that PM concentrations are increasing with increasing wind speed. High wind speeds caused lower concentrations, as a consequence of mixing and dilution of the air pollutants. Wind turbulence with large mixing height results in proper dilution and dispersion of pollutants during 
summer. In Chennai maximum mixing height is lower in post monsoon $(1063.75 \mathrm{~m})$ compared to that of winter $(1274.45 \mathrm{~m})$ and summer $(1010.5 \mathrm{~m})$ [19].

\subsubsection{Effects of temperature}

Another meteorological factor which affects the PM concentration is temperature. Chennai city lies on the thermal equator-and is also on the coast, which prevents extreme variation in seasonal temperature. The daily average temperature values in the classroom ranged from about $21.6^{\circ} \mathrm{C}$ to $31.1^{\circ} \mathrm{C}$. Obviously, the temperature was the highest in summer and the lowest in winter. Like wind speed temperature also shows inverse relationship (Fig. 4). Temperature showed negative correlation with PM indicating that temperature lowers down indoor PM. Low temperature will favour low mixing height, which in turn prevents the dispersion of pollutants.

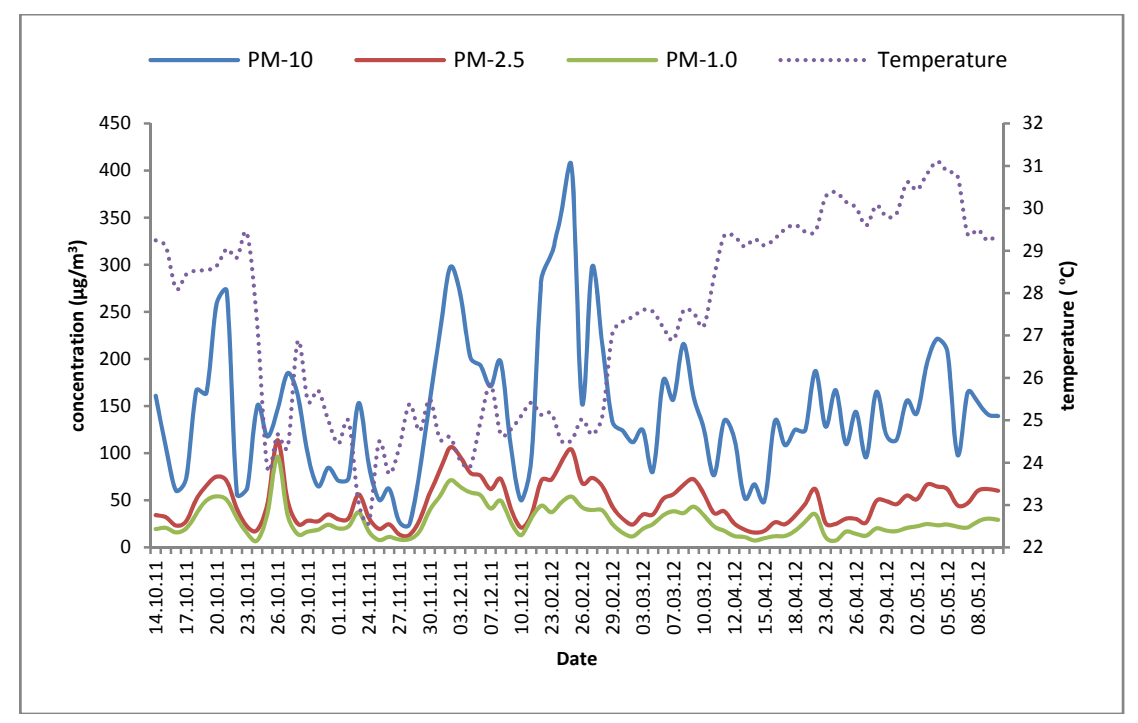

Figure 4: $\quad$ Time series of PM concentrations and temperature.

\subsubsection{Effects of relative humidity}

Figure 5 shows the daily variation in humidity and PM concentrations in different seasons. Obviously, humidity was the highest in monsoon $(80.57 \%)$ and the lowest in summer $(72.31 \%)$. Rainfall might be the reason for the higher humidity in monsoon whereas the higher temperature in summer might be the reason for lower humidity. Time series of $\mathrm{PM}_{10}, \mathrm{PM}_{2.5}, \mathrm{PM}_{1}$ and relative humidity was presented in figure 5. It is found that as RH increases, the PM concentrations were found to be decreasing. Since increased outdoor humidity is associated with rainy days it might have washed out pollutants and lower the outdoor concentration. 


\subsubsection{Effects of rainfall}

Figure 6 show the times series plot of daily average PM concentrations and rainfall. During the study period, there was no rain in winter and summer seasons. Therefore, no graphs were plotted for these seasons. Lower aerosol concentrations were observed in the rainy days because of the washout effect of particles from the atmosphere. Larger super-micron particles are removed faster during monsoon than submicron particles and have little effect on their

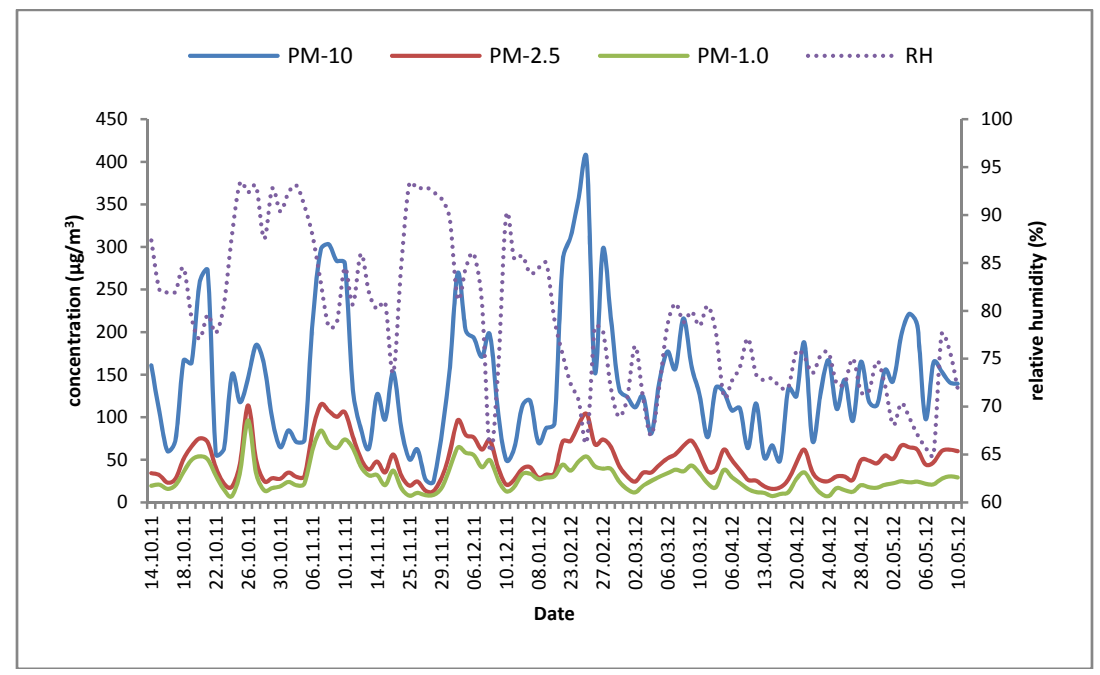

Figure 5: Time series of PM concentrations and relative humidity.

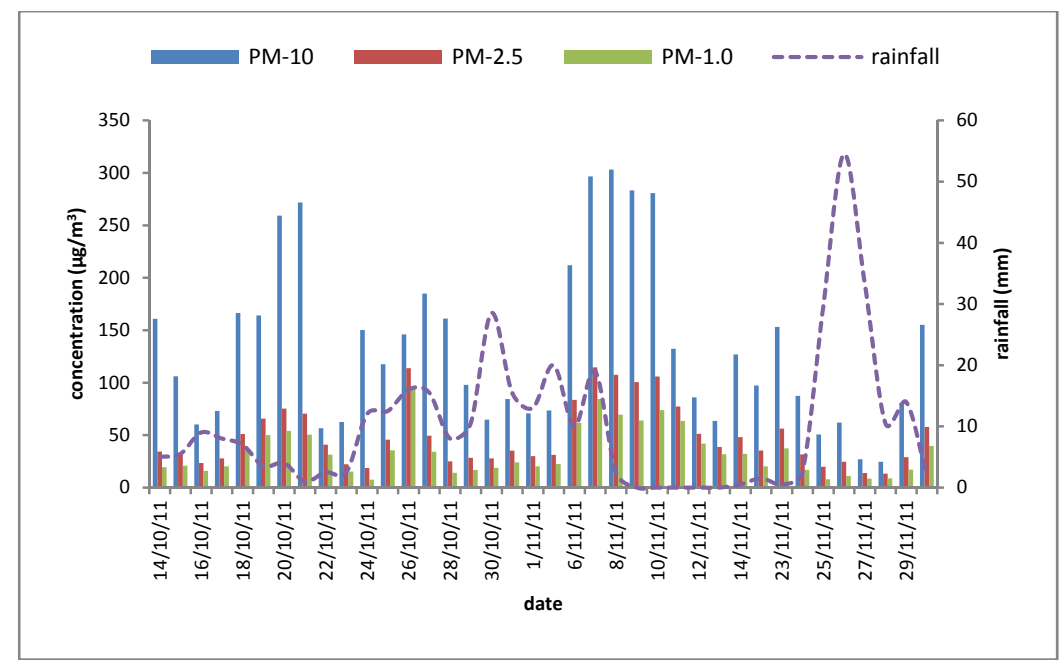

Figure 6: Time series of PM concentrations and rainfall. 
concentration. Coarse particles on absorbing water settle down and therefore resuspension and re-entrainment of soil is minimal and particulate during the monsoon is mainly composed of finer particles indoor as well as outdoors.

\section{Conclusions}

The goal of this study was to characterize seasonal, variations in $\mathrm{PM}_{10}, \mathrm{PM}_{2.5}$ and $\mathrm{PM}_{1}$ concentrations of a primary classroom in the urban area of Chennai, India. For this purpose $\mathrm{PM}_{10}, \mathrm{PM}_{2.5}$ and $\mathrm{PM}_{1}$ concentrations were monitored inside a classroom during winter, summer and monsoon seasons. Results indicated that outdoor traffic emissions as well as indoor activities influenced the fine and coarse particulate concentrations of the classroom. The PM concentrations showed a clear seasonal variation with highest concentrations occurred during winter followed by monsoon and summer. The high concentration in winter was due to low wind speed and temperature. Summer was observed to be the cleanest period with respect to PM concentration (with in NAAQS limit) due to better dispersion conditions. The study concluded that meteorological conditions are one of the predominant factors governing PM concentration in the indoor environment.

\section{Acknowledgements}

We wish to thank the Ministry of Environment and Forests, Government of India, New Delhi for funding this study. We also express our sincere thanks to the students, teachers and staff of the Kendriya Vidyalaya School, CLRI campus, Chennai for their support and cooperation in carrying out this study.

\section{References}

[1] World Health Organization, Health Aspects of Air Pollution with Particulate Matter, Ozone and Nitrogen Dioxide, Report on a WHO Working Group Bonn, Germany. 2003.

[2] Neuberger, M., Schimek, M. G., Horak Jr, F., Moshammer, H., Kundi, M., Frischer, T., Gomiscek, B., Puxbaum, H., \& Hauck, H., Acute effects of particulate matter on respiratory diseases, symptoms and functions: epidemiological results of the Austrian Project on Health Effects of Particulate Matter (AUPHEP). Atmospheric Environment, 38, pp. 39713981, 2004.

[3] Wallenborn, J. G., Schladweiler, M. J., Richards, J. H., \& Kodavanti, U. P., Differential pulmonary and cardiac effects of pulmonary exposure to a panel of particulate matter-associated metals. Toxicology and Applied Pharmacology, 241, pp. 71-80, 2009.

[4] Mate, T., Guaita, R., Pichiule, M., Linares, C., \& Diaz, J., Short-term effect of fine particulate matter (PM2.5) on daily mortality due to diseases 
of the circulatory system in Madrid (Spain). Science of the Total Environment, 408, pp. 5750-5757, 2010.

[5] Miller, F. J., Dosimetry of particles: critical factors having risk assessment implications. Inhal Toxicol, 12, pp. 389-95, 1999.

[6] Central Pollution Control Board, Air quality monitoring, emission inventory and source apportionment study for Indian cities, National Summary Report. 2010.

[7] Bruce, N., Perez-Padilla, R., \& Albalak, R., Indoor air pollution in developing countries: a major environmental and public health challenge, Bulletin of the World Health Organization, 78, pp. 1078-1092, 2000.

[8] Smith, K. R., National burden of disease in India from indoor air pollution, Proceedings of the National Academy of Sciences, 97, pp. 13286-13293, 2000.

[9] Chan, A. T., Indoor-outdoor relationships of particulate matter and nitrogen oxides under different outdoor meteorological conditions. Atmospheric Environment, 36, pp. 1543-1551, 2002.

[10] Massey, D., Kulshrestha, A., Masih, J., \& Taneja A., Seasonal trends of PM10, PM5.0, PM2.5 \& PM1.0 in indoor and outdoor environments of residential homes located in North-Central India, Building and Environment, 47, pp. 223-231, 2012.

[11] IMD, http://www.imdchennai.gov.in/hydro.gif.

[12] Thatcher, T. L., \& Layton, D.W., Deposition, resuspension, and penetration of particles within a residence, Atmospheric Environment, 29, pp. 1487-97, 1995.

[13] Branis, M., Rezacova, P., \& Domasova, M., The effect of outdoor air and indoor human activity on mass concentrations of $\mathrm{PM}_{10}, \mathrm{PM}_{2.5}$, and $\mathrm{PM}_{1}$ in a classroom. Environmental Research, 99, pp. 143-149, 2005.

[14] Poupard, O., Blondeau, P., Iordache, V., \& Allard, F., Statistical analysis of parameters influencing the relationship between outdoor and indoor air quality in schools. Atmospheric Environment, 39, pp. 2071-2080, 2005.

[15] Fromme, H., Twardella, D., Dietrich, S., Heitmann, D., Schierl, R., Liebl, B., \& Ruden, H., Particulate matter in the indoor air of classroomsexploratory results from Munich and surrounding area. Atmospheric Environment, 41, pp. 854-86, 2007.

[16] Stranger, M., Vermaak, S. S. P., \& Grieken R., V., Characterization of indoor air quality in primary schools in Antwerp, Belgium. Indoor Air, 18, pp. 454-463, 2008.

[17] Chithra, V. S., \& Nagendra, S. M. S., Indoor air quality investigations in a naturally ventilated school building located close to an urban roadway in Chennai, India, Building and Environment, 54, pp. 159-167, 2012.

[18] Attri, S.D., Siddhartha Sing, Mukhopadhyay B., \& Bhatnagar A. K., Atlas of hourly mixing height and assimilative capacity of atmosphere in India. India Meteorological Department, New Delhi. 2008. 